\title{
Energy and Environmental Analysis of a Solar Evacuated Tube Heat Pipe Integrated Thermoelectric Generator Using IoT
}

\section{SakthiPriya Manivannan}

Vellore Institute of Technology: VIT University

DivyaLaxmi Gunasekaran

Vellore Institute of Technology: VIT University

Gowthami Jaganathan

Kongu Engineering College

\section{Shanthi Natesan}

Kongu Engineering College

\section{SabariMuthu Muthusamy}

Kongu Engineering College

\section{Sung Chul Kim}

Yeungnam University

\section{Balaji Kumar}

Vellore Institute of Technology: VIT University

GaneshKumar Poongavanam ( $\nabla$ selgan.cad@gmail.com )

Yeungnam University https://orcid.org/0000-0003-3971-2454

\section{Sakthivadivel Duraisamy}

Vellore Institute of Technology: VIT University

\section{Research Article}

Keywords: Solar evacuated tube heat pipe, thermoelectric generator, parabolic trough concentrating collector, Environmental analysis, internet of things, boost converter

Posted Date: January 7th, 2022

DOI: https://doi.org/10.21203/rs.3.rs-1144251/v1

License: (1) (1) This work is licensed under a Creative Commons Attribution 4.0 International License.

Read Full License 
Version of Record: A version of this preprint was published at Environmental Science and Pollution Research on March 31st, 2022. See the published version at https://doi.org/10.1007/s11356-022-19857w. 


\section{Energy and Environmental analysis of a Solar Evacuated Tube Heat Pipe integrated Thermoelectric Generator using IoT}

${ }^{\text {a}}$ SakthiPriya Manivannan, ${ }^{\mathrm{a}}$ DivyaLaxmi Gunasekaran, ${ }^{\mathrm{b}}$ Gowthami Jaganathan, ${ }^{\mathrm{b}}$ Shanthi Natesan,

${ }^{\mathrm{b}}$ SabariMuthu Muthusamy, ${ }^{\mathrm{c}, 1}$ Sung Chul Kim, ${ }^{\mathrm{a} B a l a j i}$ Kumar, ${ }^{\mathrm{c}, *}$ GaneshKumar Poongavanam, and a,1*Sakthivadivel Duraisamy

${ }^{a}$ School of Mechanical Engineering, Vellore Institute of Technology, Vellore-632014, Tamil Nadu, India.

${ }^{b}$ Kongu Engineering College, Erode, Tamilnadu-638060, India.

${ }^{c}$ School of Mechanical Engineering, Yeungnam University, Gyeongbuk 712-749, Republic of Korea.

${ }^{1}$ Authors contributed equally to this work.

\section{Abstract} a thermoelectric generator (TEG) using the internet of things (IoT). The TEGs convert heat energy into electricity through the Seebeck effect that finds application in the waste heat recovery process for the generation of power. The present work deals with the theoretical study on solar evacuated tube heat pipe integrated TEG and it is validated experimentally using with and without parabolic trough concentrating collector. And the carbon credit of the TEG system is determined to find its potential in the environmental aspect. Also, the boost type converter is used to raise the power output by increasing the voltage from the TEG for rural electrifications. However, it is found that the maximum power output due to the influence of the parabolic trough concentrator results in increased efficiency when compared with the nonconcentrating SEHP-TEG system. The TEG output power can be boosted up to a maximum of $5.98 \mathrm{~V}$ using a power electronic boost converter. Besides, the recorded real sensor data with Arduino is implemented in the experimental process for automatic remote monitoring of the temperature.

Keywords: Solar evacuated tube heat pipe, thermoelectric generator, parabolic trough concentrating collector, Environmental analysis, internet of things, boost converter. 


\section{Introduction}

In today's world, one of the major concerns was to provide clean energy for a hazardous-free environment (Zoui et al. 2020). As of now, in the total energy consumption, about $80 \%$ is fossil fuel's contribution and the remaining is from other sources such as nuclear power, hydro, and renewable energy sources like solar, biofuels (Bildirici, 2018), wind, and geothermal energy (Faik Bilgili, 2020). But in the current state, fossil fuels are in the urge of depletion, and in the meantime, it is expected that due to the increase in the global population the electricity demand can be increased by $49 \%$ by the year 2040 (CAPP 2018). Furthermore, the use of fossil fuels leads to a rapid increase in greenhouse gas emissions, which has an impact on the world's longterm growth due to global warming, climate change, and other factors (Yousefi et al. 2016, Veronesi et al. 2017). Matching the gap between the depletion of fossil fuels and the growing population will lead us to depend on alternative fuels like renewable energy sources. One such renewable energy is solar which is of clean energy source and is feasible, therefore it has a significant part in reducing the global crisis for energy. In this context, thermoelectric technology would also be a suitable energy source for the future as it directly converts the energy from one form to another without affecting the environment (Karthick et al. 2019). Thermoelectric technology (TE) is an eco-friendly technology that does not pollute any greenhouse gases and also has longer life since it has no moving parts (Ahıska and Mamur 2016). TE uses both the Seebeck (Thermoelectric generators) and Peltier effect (Thermoelectric coolers). In this, thermoelectric generators (TEGs) which work on the Seebeck effect converted to electrical energy from thermal energy (Verma et al. 2021). TEGs have superabundant advantages compared with other renewable energy devices as it is solid-state, clean energy conversion, cost-effective, and environmentally friendly (Enescu 2019). In addition to some conventional heat recovery applications, the heat pipe technology with solar concentrators would efficiently enhance the heat and mass transfer performance for cogeneration and one such is the hybrid solar water heating system with evacuated tube heat pipe along with the TEG and cooling jackets to produce combined heat and power (He et al. 2012; Lv et al. 2017; Ong et al. 2017). Typically, a cogeneration system produces electrical energy of $0.19 \mathrm{kWh}$ and 300 liters of hot water in a day at $55^{\circ} \mathrm{C}$ for solar insolation below $1000 \mathrm{~W} / \mathrm{m}^{2}$. The obtained electrical power output is $64.80 \mathrm{~W}$ and the efficiency of the collector and electrical efficiency of thermoelectric modules is $47.54 \%$ and $1.59 \%$ respectively (Zhang et al. 2013). In this regard, the thermoelectric generator may be chosen due to advantages such as improved heat transfer characteristics on both sides of the thermoelectric generator due to 
the greater heat transfer area. TEGs are also used in the waste heat recovery system such as exhaust from the car for electricity generation and this helps in reducing fuel consumption. Heat pipes and TEGs can thus be employed in automobile applications due to their small size and solid-state nature (Orr et al. 2016). With increasing vehicle speed, which raises the hot junction temperature, the TEG's performance improves due to higher exhaust temperature, flow rate, and heat conduction via the TEG leg from the hot junction.(Yu et al. 2015). The nanostructured thermoelectric materials are used in flat-panel thermoelectric generators for achieving high performance (Kraemer et al. 2011). A comparison of the flat plate and annular thermoelectric generators were conducted, in this, the latter has attained higher heat transfer at standard solar radiation, and they have produced $1.92 \mathrm{~W}$ power output with an electrical efficiency of 2.63\% (Manikandan and Kaushik 2016). While considering the materials for thermoelectric generators, bismuth telluride alloys are a suitable one and can maintain a maximum figure of merit at a temperature of $500 \mathrm{~K}$ (Goldsmid 2014) and can produce an electrical power of $14.1 \mathrm{~W}$ for hot and cold side temperatures of $250^{\circ} \mathrm{C}$ and $50^{\circ} \mathrm{C}$ respectively (Karabetoglu et al. 2012). Low convergence efficiency harms the growth of thermoelectric generators in the power generation sector, thus attention must be paid to the geometric configuration. The leg pin of thermoelectric generators can help enhance system efficiency by lowering thermal conductance (Ali et al. 2014). Likewise, if TEG's substrate area increases, then its output also increases as it increases the thermal concentration ratio and this was analyzed using ANSYS v12.0.1 (Chen et al. 2013). And the TEG performance was enhanced by the optimization of heat sink design using finite element numerical method and observed that the frontal area is increased by decreasing the length and this seems to be the best approach (Wang et al. 2012). To monitor the temperature of the cold and hot sides of the TEGs, temperature sensors can be integrated with IoT for accuracy. Nowadays the role of Information and Communication Technology (ICT) has enhanced a lot with the emergence of IoT in every sector (Rozik et al. 2016). The significant thing with IoT is that it can easily collaborate as a part with any domain or application. The thermoelectric generator's progress using the IoT system which helps in providing the sustainable power supply by the integration of wireless sensor networks (Park et al. 2019). The IoT based technology is used for monitoring and controlling double pipe heat exchanger (Sridharan et al. 2018) and observed that the temperature and mass flow can be measured without manpower by the way of creating channels and by collecting, analyzing, and visualizing data, acting on the data according to the required situation. This type of control system helps in continuous and appropriate operation. Since the voltage obtained from the system is low and therefore it finds difficulty in the applications. 
102 And this can be managed by the usage of a DC-DC converter by boosting the output voltage

103 (Park et al. 2019).

104 Thus, thermoelectric generators can be utilized as an alternative energy source since they are a 105 green energy technology that can produce electricity from waste heat energy, lowering energy 106 costs, reducing environmental impacts, and reducing the usage of fossil fuels. As a result, this 107 technology has been identified as being vital in the heat recovery process as well as a viable 108 alternative to the traditional method. The integration of IoT TEGs leads to a long-term power 109 supply. The present paper investigates the thermoelectric generator's (TEGs) whose role is to 110 convert the heat energy from the solar evacuated tube heat pipe system to electrical energy 111 using with and without a concentrating collector with the output being monitored by an IoT 112 system and further the electrical output is boosted by the boost converter.

\section{2. Experimental Setup}

115 The system comprises an individual evacuated tube heat pipe collector as shown in Fig 116 1. It is exposed to sunlight equipped with two thermoelectric modules and cooling fans on the 117 condenser part for the production of electricity. Solar evacuated tube heat pipe is exposed to 118 sunlight tends to absorb heat through copper heat pipe having evaporator, adiabatic section, 119 and condenser part filled with low boiling Ammonia as working fluid for repeated evaporation 120 and condensation. The maximum amount of heat is absorbed in the evaporator followed by the 121 adiabatic section is transferred to the condenser part of the heat pipe which is coupled with the 122 aluminium (Al) bars attached with TEG as shown in Fig 1. The heat is then generated across 123 the heat spreader $\mathrm{Al}$ bar to the hot junction and ejected at the cold junction of thermoelectric 124 modules. The cold side of the TE module makes close contact with the Al fins cooling jacket 125 which enables the airflow and gets heated up. Due to the difference of temperature across the 126 surfaces of the thermoelectric module, DC power is produced by the Seebeck effect. In 127 addition, the heat energy received by the air is used for preheating, increasing the system's total 128 effectiveness. 


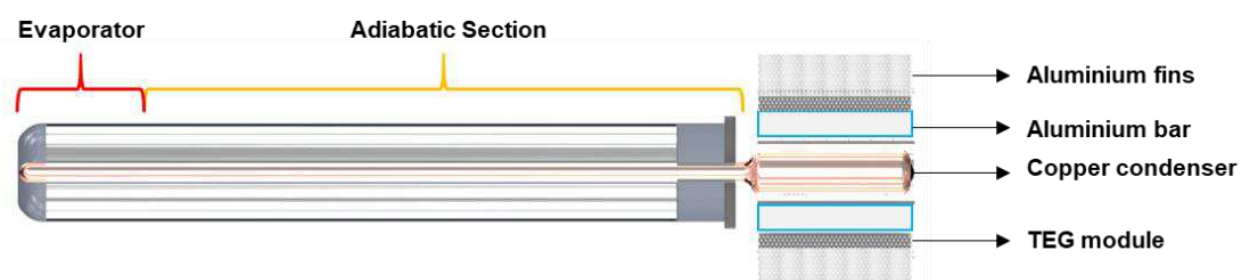

130

131

132

133 The parabolic trough collector (PTC) system is covered with a high reflective aluminum sheet

134 to achieve high reflectivity for better concentration. The proposed SEHP-TEG system is placed 135 136

137

140 The SEHP's condenser is equipped with an aluminium block and two TEG modules with Al

141 heat sinks as shown in Fig 2(b). TEG modules are placed between aluminium heat spreader

142 blocks that spread the heat from the condenser and the heat sink Al fins jacket to produce as

143 much of a temperature gradient as possible for maximum TEG module power generation. The

144 non-hardening thermal adhesive paste is used on the surfaces of the Al heat spreader and heat 145 sink to avoid air gaps for better heat transfer and to maintain thermal conductivity. (a)

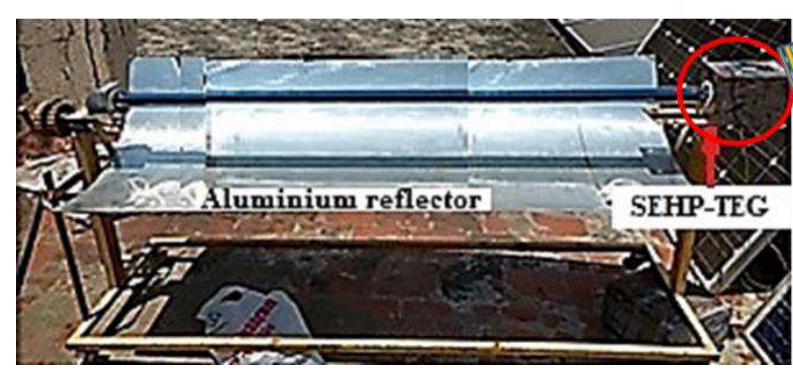

Fig 2. Experimental setup of SETHP-TEG 

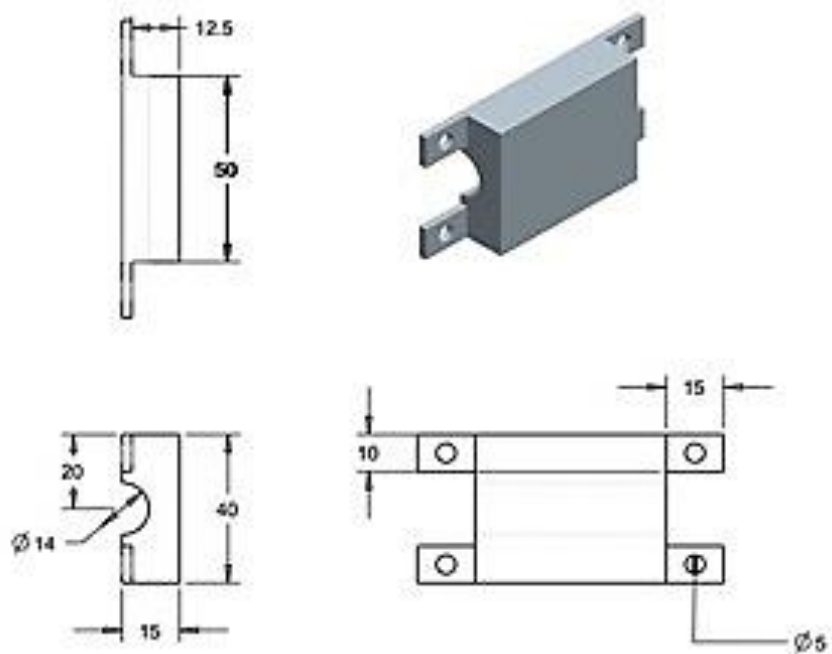
(

Fig 3. Aluminium block and its dimensions

The Al block is $12.5 \mathrm{~mm}$ in width, $50 \mathrm{~mm}$ in length, and a $25 \mathrm{~mm}$ blind diameter hole is bored fit on the heat pipe's condenser section as shown in Fig 3. Two Laird Technologies thermoelectric (TE) modules (Model - TEC-12706) each have a dimension of 40x40x3.3 mm are attached to the two sides of the Al block. The generated voltage and current across each module are measured using a digital multimeter with an uncertainty of $\pm 3 \%$. The product of voltage and current is used to calculate the power generated by each TE module. The inclination angle of the SEHP with and without PTC is kept at $13^{\circ}$ throughout the experimentation. Solar radiation was recorded using Kipp and Zonen pyranometer with an uncertainty of $\pm 3 \%$. A 12 $\mathrm{V}$ DC cooling fan is used to evacuate the temperature of the cold side to maximize $\Delta \mathrm{T}$ of the TEG. After fixing the heat source, heat sink, and Al plate with SEHP, the experiment is conducted in a specified interval for with and without PTC and observations have been tabulated.

A pilot experiment was undertaken for analyzing the performance of the SETHP-TEG system based on the thermodynamic relations. The temperature was measured using thermocouples affixed to various surfaces, which were obtained via the IoT logger. This arrangement has the benefit of providing electrical power output and avoidance of manpower with the help of IoT technology. The temperature was measured using thermocouples affixed to various surfaces, which were obtained via the IoT logger. The TE module's output was connected to an electronic load with variable resistance. (1) 


\section{Thermodynamic Modelling of SETHP- TEG}

173 The following assumptions were considered for the thermodynamic modeling and SEHP-TEG 174 analysis:

a. One Dimensional steady-state conductive heat transfer is considered for the analysis.

Heat energy supplied from the condenser part of SEHP is absorbed by the Al bars at the hot junction $\left(\mathrm{Q}_{\mathrm{h}}\right)$ and can be obtained by doing the energy balance at the hot junction of the TEG as,

b. The thickness (d) of the thermoelectric (TE) module is kept constant.

c. The losses due to convection and radiation from the sides of the TE module are neglected.

d. The cold side temperature of the TE module is assumed to be constant.

186 it's written as:

$$
\mathrm{Q}_{\mathrm{c}}=\alpha \mathrm{IT}_{\mathrm{c}}+\frac{\mathrm{I}^{2} \mathrm{R}}{2}+\mathrm{K}\left(\mathrm{T}_{\mathrm{h}}-\mathrm{T}_{\mathrm{c}}\right)+\frac{\tau\left(\mathrm{T}_{\mathrm{h}}-\mathrm{T}_{\mathrm{c}}\right)}{2} \times \mathrm{n}
$$

\subsection{Power and efficiency analysis}

The power output, electrical energy efficiency, electrical exergy efficiency, and the thermal efficiency of the SEHP-TEG system can be written as,

The maximum output power is calculated as

$$
P_{\text {max }}=V_{\text {max }} \times I_{\max }
$$

194 The maximum voltage and current expression as

$$
\begin{aligned}
& V_{\text {max }}=V_{o c} / 2 \\
& I_{\text {max }}=I_{s c} / 2
\end{aligned}
$$

197 The open circuit and voltage are calculated as

$$
\mathrm{V}_{\mathrm{oc}}=2 \alpha \times \mathrm{N} \times \Delta \mathrm{T}
$$

$$
\mathrm{I}_{\mathrm{sc}}=(\alpha / \rho) \times(\mathrm{A} / \mathrm{L}) \times \Delta \mathrm{T}
$$

200 The electrical and thermal efficiencies of the TE module can be expressed as

$$
\eta_{e l}=\frac{P_{\max }}{Q_{\text {in }}}=\frac{P_{\max }}{G \times A_{a b s} \times a_{\text {tube-in }} \times t_{\text {tube-out }}} \times n
$$

\section{Environmental Analysis}


204 For a low-carbon society, life cycle $\mathrm{CO}_{2}$ emission assessment has been chosen as a parameter for environmental analysis. And here the main focus is on carbon dioxide emission since it has 206 a greater impact compared to other greenhouse gases. As a result, scenario analysis is 207 formalized for TEGs alone in the context of solar thermal systems. The reason for choosing 208 TEG is that it has the potential of changing waste heat energy into useful electricity in various 209 sectors and there is a need for analyzing its environmental impact as it is an emerging 210 technology for power generation. Since solar thermal system (Concentrating technology) is of 211 renewable energy source which has lower emission compared to other conventional system 212 and many analyses has been carried out in this aspect. Hence coupling this technology with 213 the TEGs is for greater technological feasibility as well as in economical aspect, since it is the 214 mere future.

216 Table 1. TEGs performance, $\mathrm{CO}_{2}$ emissions, and cost (Kishita et al. 2014, 2016)

\begin{tabular}{|c|c|c|}
\hline Item & Value & Reference \\
\hline Conversion efficiency & $\begin{array}{l}7.2 \% \\
17.72 \%\end{array}$ & $\begin{array}{l}\text { The conversion efficiency is } 7.2 \% \text { in } 2013 ; 17.7 \% \\
\text { by } 2030 \text { according to (Kishita et al. 2014). }\end{array}$ \\
\hline Maximum electric output & $184 \mathrm{~W}$ & $\begin{array}{l}\text { Estimated by the author considering } 2 \text { modules in } \\
\text { usage. }\end{array}$ \\
\hline TEG Cost & $\$ 6.20$ & $\begin{array}{l}\text { TGE unit price is } \mathbf{\$ 3 . 1 0} \text { (Full Battery). And here } \\
2 \text { TEG modules are considered. Likewise, other } \\
\text { accompanying costs are not considered. }\end{array}$ \\
\hline $\begin{array}{l}\mathrm{CO}_{2} \text { emissions of } \\
\text { producing thermoelectric } \\
\text { materials - Bi-Te }\end{array}$ & $\begin{array}{l}14.78 \mathrm{~kg} \text { of } \\
\mathrm{CO}_{2} / \text { module }\end{array}$ & $\begin{array}{l}\text { Likewise, the TEG unit has } 2 \text { modules. The } \mathrm{CO}_{2} \\
\text { emission of producing thermoelectric materials } \\
\text { Bi-Te is } 7.39 \mathrm{~kg} \text { of } \mathrm{CO}_{2} / \text { module. }\end{array}$ \\
\hline $\begin{array}{l}\mathrm{CO}_{2} \text { emissions of } \\
\text { producing the housing } \\
\text { Aluminium part }\end{array}$ & $4 \mathrm{~kg}$ of $\mathrm{CO}_{2} / \mathrm{kg}$ & (Hydro 2018b) \\
\hline $\begin{array}{l}\mathrm{CO}_{2} \text { emissions of } \\
\text { producing from casing - } \\
\text { cast iron }\end{array}$ & $\begin{array}{l}1.51 \mathrm{~kg} \text { of } \mathrm{CO}_{2} \\
/ \mathrm{kg}\end{array}$ & (Winnipeg) \\
\hline
\end{tabular}

218 The following CO2 emission per watt, $\mathrm{CO} 2$ mitigation, and carbon credits are described below,

219 and the equations are as follows -Eqn. 9 to 11 (Garud et al. 2021)

220 (i) $\mathrm{CO}_{2}$ emission per Watt of power generation:

$221 \quad \mathrm{CO}_{2}$ emission per $W$ power generated $=\frac{\text { Mass of the carbon dioxide }(\mathrm{g})}{\text { Power generated from TEG }(\mathrm{W})}$

$222 \mathrm{CO}_{2}$ emission of power generated for each configuration of TGS is presented in $\mathrm{g} / \mathrm{W}$.

223 (ii) $\mathrm{Net} \mathrm{CO}_{2}$ mitigation: 
$224 \mathrm{CO}_{2}$ emissions will be reduced as a result of TGE waste heat to power conversion. As a result, 225 in this case, net $\mathrm{CO}_{2}$ mitigation is well-defined as the total power produced (net decrease in $226 \mathrm{CO}_{2}$ emissions) by each TGE design throughout its life.

$$
\text { Net } \mathrm{CO}_{2} \text { mitigation }=E_{\text {out }} \cdot n \cdot \frac{1}{1-L_{a}} \cdot \frac{1}{1-L_{t}} \cdot 0.98
$$

228 Where,

$$
E_{\text {out }}=\text { Annual energy output }(\mathrm{kWh} / \text { year }) \text {, }
$$

$230 \quad \mathrm{~L}_{\mathrm{a}}$ and $\mathrm{L}_{\mathrm{t}}=0.2$ and 0.4 , respectively. (Assumption values -domestic appliance loss and

231 transmission appliance loss)

\section{2 (iii) Carbon credit:}

233 Carbon credit refers to the maximum amount of carbon dioxide or other greenhouse gases that 234 can be released. One credit entitles one tonne of carbon dioxide to be released into the atmosphere. For each configuration of TGS, the net $\mathrm{CO}_{2}$ mitigation in tones can be changed to carbon credit in USD dollars by considering $\mathrm{CO}_{2}$ emission is dealt at $24.85 \$$ tones of $\mathrm{CO}_{2}$ emission.

$$
\text { Carbon credit }=\mathrm{Net} \mathrm{CO}_{2} \text { mitigation } X \text { cost per tone of } \mathrm{CO}_{2} \text { mitigation (11) }
$$

\section{IoT based temperature monitoring system:}

240 Automatic remote temperature monitoring is enabled by integrating the system with IoT

241 technology to improve the proposed system's effectiveness. The hot and cold side temperatures

242 of the TE module could be remotely measured and monitored using the system setup outlined 243 in Fig 4.

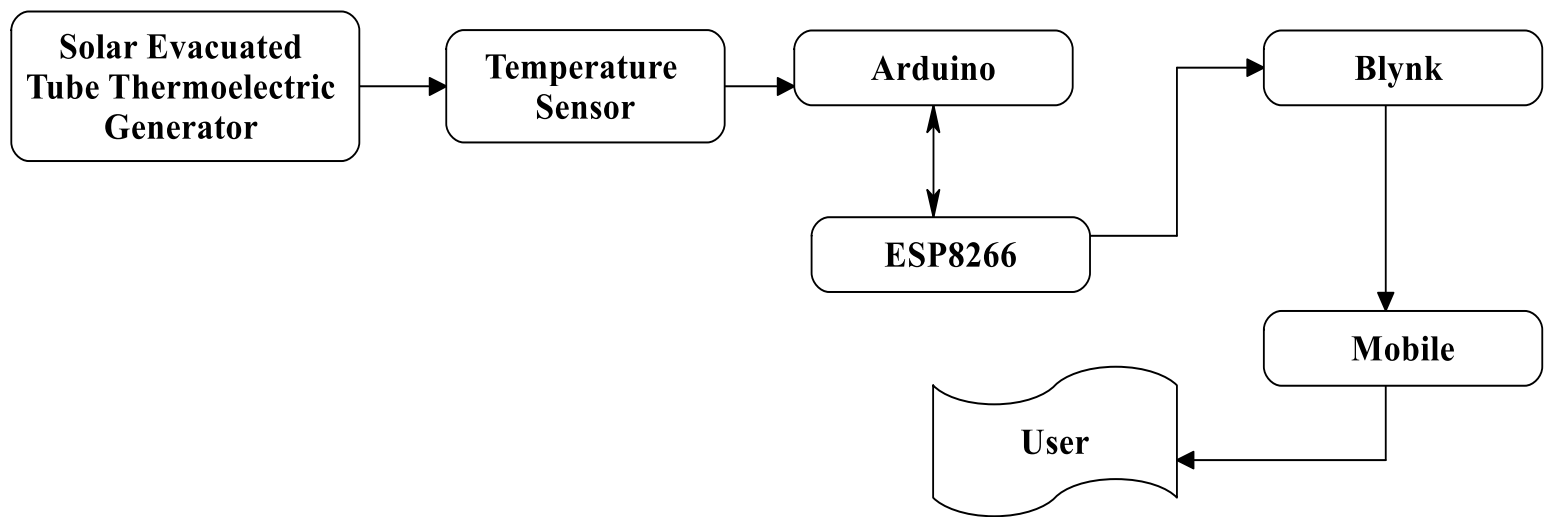

Fig 4. Block diagram of IoT integrated solar evacuated tube TEG

Table 2 Specification of IoT System

The description and specifications of the IoT systems are listed in Table 2. 


\begin{tabular}{|c|c|c|c|}
\hline S. No & $\begin{array}{l}\text { Resources } \\
\text { Required }\end{array}$ & Description & Specification \\
\hline 1 & Arduino Board (Uno) & $\begin{array}{l}\text { It is ATmega328P based } \\
\text { microcontroller. It has } 14 \text { digital and } \\
3 \text { analog input/output pins. This } \\
\text { board is programmable through } \\
\text { Arduino IDE software. }\end{array}$ & $\begin{array}{l}\text { 8-bit ATmega328P } \\
\text { microcontroller, } \\
\text { operating voltage } 5 \mathrm{~V} \\
\text { (Arduino UNO). }\end{array}$ \\
\hline 2 & Blynk & $\begin{array}{l}\text { This software is specially designed } \\
\text { for IoT data collection, remote } \\
\text { control, data storage, and } \\
\text { visualization. Three main } \\
\text { components of Blynk- Blynk } \\
\text { libraries, Server, App. }\end{array}$ & $\begin{array}{l}\text { Works well with iOS } \\
\text { and Android (Blynk). }\end{array}$ \\
\hline 3 & $\begin{array}{l}\text { Arduino software } \\
\text { (IDE) }\end{array}$ & $\begin{array}{l}\text { It contains space for several } \\
\text { components like a text editor, } \\
\text { console, serial monitor, and several } \\
\text { other menus. It provides an } \\
\text { environment to upload code into the } \\
\text { hardware and to communicate with } \\
\text { it. }\end{array}$ & $\begin{array}{l}\text { Can be installed with } \\
\text { Windows, Linux, and } \\
\text { Mac OS (Arduino } \\
\text { Software (IDE)). }\end{array}$ \\
\hline 4 & Sensor- LM35 & $\begin{array}{l}\text { Its output voltage is linearly } \\
\text { proportional to the Centigrade } \\
\text { temperature. It draws only } 60 \mu \mathrm{A} \\
\text { from the supply. It is rated to } \\
\text { operate over a }-55^{\circ} \mathrm{C} \text { to } 150^{\circ} \mathrm{C} \\
\text { temperature range }\end{array}$ & $\begin{array}{lr} \pm 0.5^{\circ} \mathrm{C}, & 4 \mathrm{~V}-30 \mathrm{~V}, \\
\text { Temperature } & \text { sensor } \\
\text { with analog } & \text { output } \\
\text { (Texas Instruments). }\end{array}$ \\
\hline 5 & $\begin{array}{l}\text { Wi-Fi } \\
\text { ESP8266 }\end{array}$ & $\begin{array}{l}\text { This is a Wi-Fi MCU, have the } \\
\text { capability of a 32-bit } \\
\text { microcontroller }\end{array}$ & $\begin{array}{l}\text { Power- } 3.3 \mathrm{~V}, 16 \text { GPIO } \\
\text { pins (Espressif Systems; } \\
\text { Sparkfun ALC) . }\end{array}$ \\
\hline 6 & Jumper Wires & $\begin{array}{l}\text { This is to make interconnections } \\
\text { between Arduino, breadboard, } \\
\text { sensors, and other components }\end{array}$ & $150 \mathrm{~mm}$ length \\
\hline
\end{tabular}




\begin{tabular}{lll}
\hline 7 Power supply & Constant power is to be supplied for & Power is supplied by a \\
prolonged functioning of Arduino, & USB link connected \\
LM35, and ESP8266 & with PC
\end{tabular}

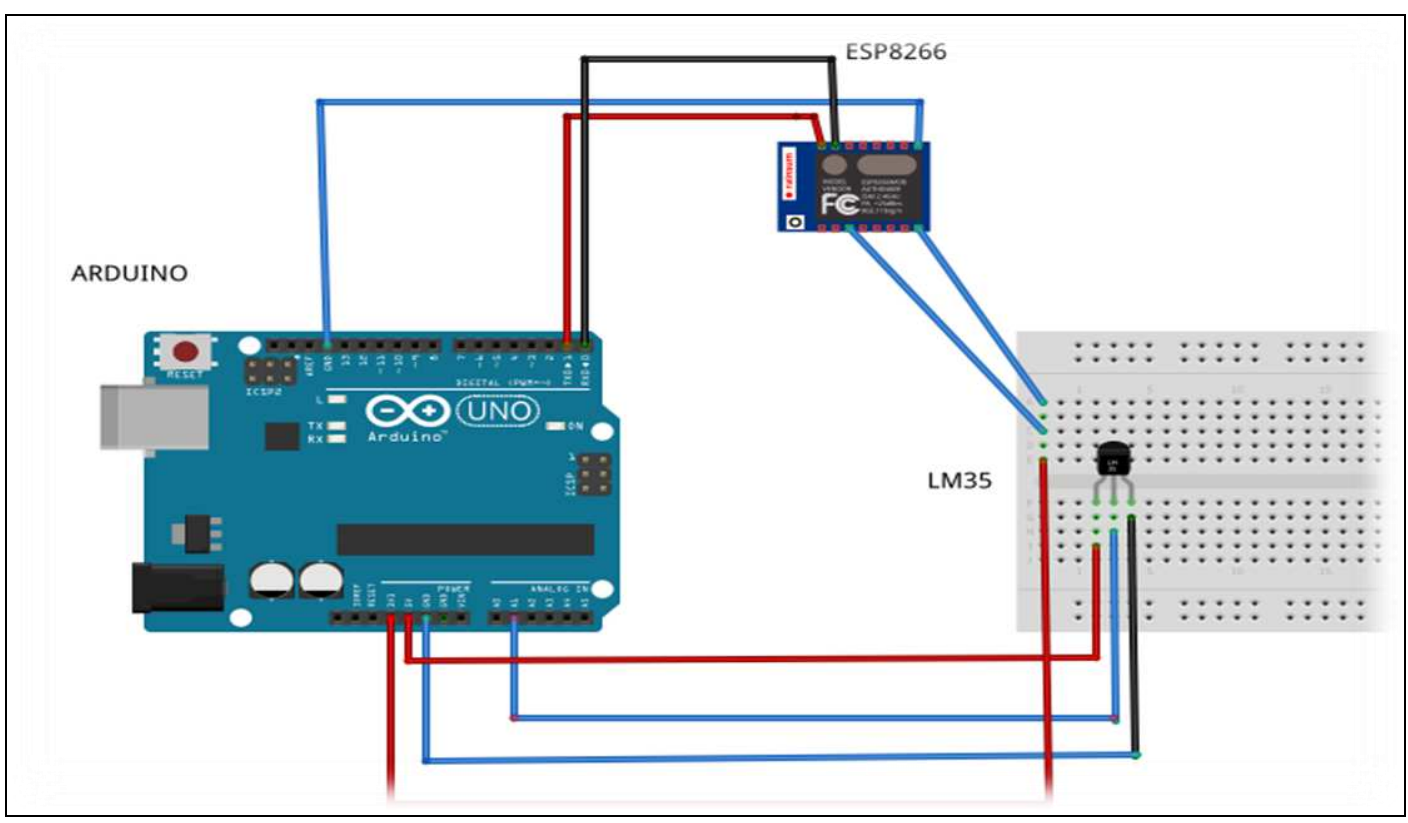

Fig 5. Circuit diagram of the proposed IoT system components

The circuit connections for the IoT-based temperature monitoring system are depicted in Fig 5. The following are the procedures adopted for the implementation of the IoT system with the SEHP-TEG system:

- Interfacing of sensors with Arduino - Temperature sensor LM35 is used to remotely monitor the temperature on the sides of the TE module. The sensor's output voltage is proportional to the temperature it measures.

- Interfacing of Wi-Fi module with Arduino - The Arduino board was connected with the Internet through ESP8266 Wi-Fi module (other modes such as GSM, Ethernet, Bluetooth, USB (Serial), etc.) with proper AT (ATtention) commands for controlling (Espressif Systems) and to ensure whether the system is working or not (the communication between the device and its application).

○ Programming in Arduino - Arduino software is an IDE for writing and uploading the programs into Arduino software. In the proposed system, Analog pin A1 is connected to the $\mathrm{V}_{\text {out }}$ pin of LM35 to collect the output. 
- Channel creation for Linking the Arduino and Blynk - After the successful creation of the channel in Blynk, the corresponding token will be sent to the registered Blynk mail-id. The Blynk server and Arduino device are connected using this auto-generated token. The correspondence is to be inserted into the program in the Arduino IDE.

- Monitoring the data in real-time - Eventually, with the help of Blynk libraries, the collected data has been stored in the Blynk server and it is accessed through the Blynk App.

\section{Boost converter for rural applications}

As the name implies, a boost converter is one of the most basic forms of the switch-mode converter. Its purpose is to increase the input voltage. An inductor, a semiconductor switch, a diode, and a capacitor with a source for a periodic square wave are the main components of the proposed boost converters. Modern high-frequency switching power supplies are built on the foundation of DC-DC converters. However, maintaining a constant DC output voltage level for diverse DC input voltage levels is critical. In the power converter, a control circuit is employed to calculate the voltage output against the internal reference voltage. (Eydi et al. 2019). When the output deviates from its predetermined value, output control is used to offer smooth acceleration control, high efficiency, and quick dynamic response.

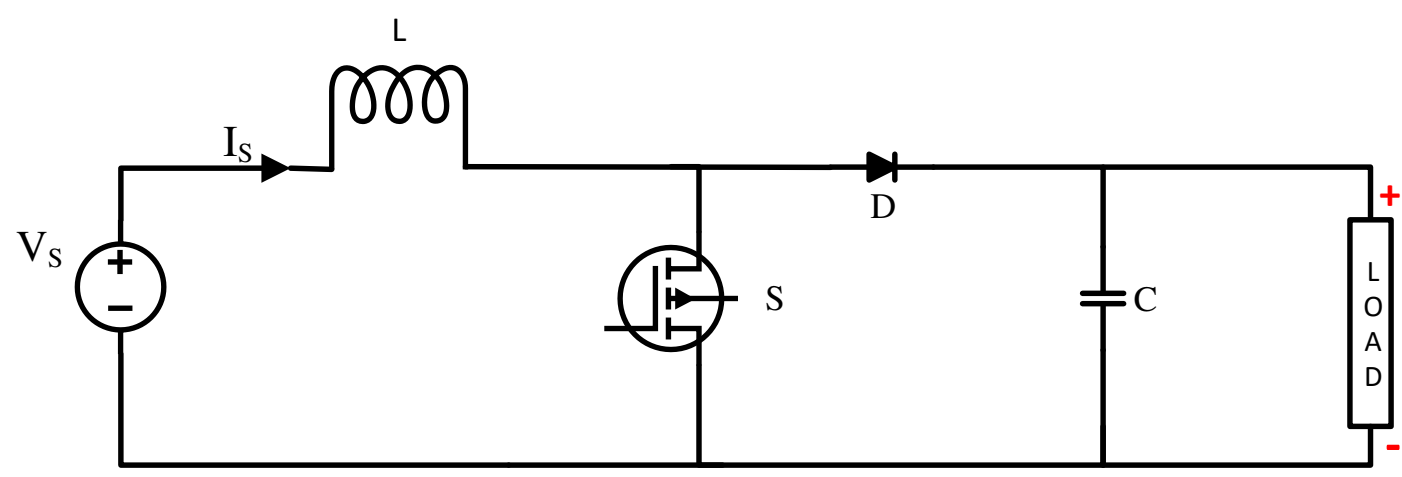

Fig 6. Boost converter block diagram

$$
{\frac{V_{o}}{V_{i n}}}_{\text {in }}=\frac{1}{1-D}
$$

Equation 12 gives the boosted output voltage considering the output voltage as an input.

\section{Results and Discussion}

From the standpoint of the application, the combined performance of the solar heat pipe and TEGs is significant. The temperature gradient has a significant impact on TEG output performance because of the heat flux distribution from side to side across the hot and cold 
299 connections of the TE module. The temperature distribution rate at the hot side of the TE

300 module hinge on the heat transfer capacity of the solar heat pipe, the connectivity with the Al

301 block and the condenser part. Similarly, temperature distributions on the Al blocks coupled

302 with the hot side of the TE module affect the electrical power generated from the TE module.

303 Meanwhile, due to the low thermal conductivity of the TE modules, the heat transfer

304 performance of TEG affects the heat transfer performance of heat pipes. As a result,

305 investigating the heat transfer coupling performance between heat pipes and TEGs is critical

306 for further promoting and optimizing SEHP-TEG performance.

307 The effect of the ambient temperature is substantial for the SEHP-TEG system, and the

308 output power fluctuations among the various temperature in the environment became evident

309 with the different temperature gradients. Ambient temperature forced at the cold junction of

310 the TE module can affect the output performance, hence the ambient temperature of $30^{\circ} \mathrm{C}$ was

311 considered for the theoretical analysis to obtain the electrical power. The hot and cold side

312 temperatures of the TE module were found to be significantly high when the ambient

313 temperature was raised. The output power was observed to be low for the high temperature at

314 the cold side of the TEG. If the connectivity between the Al block and hot side of TEG is kept

315 proper, the losses can be reduced. Furthermore, the TEGs are connected in series on four sides

316 of the Al blocks, the output power produced varies little depending on the ambient temperature

317 is comparatively small.

7.1 Experimental Performance parameters of SETHP-TEG without concentrating collector

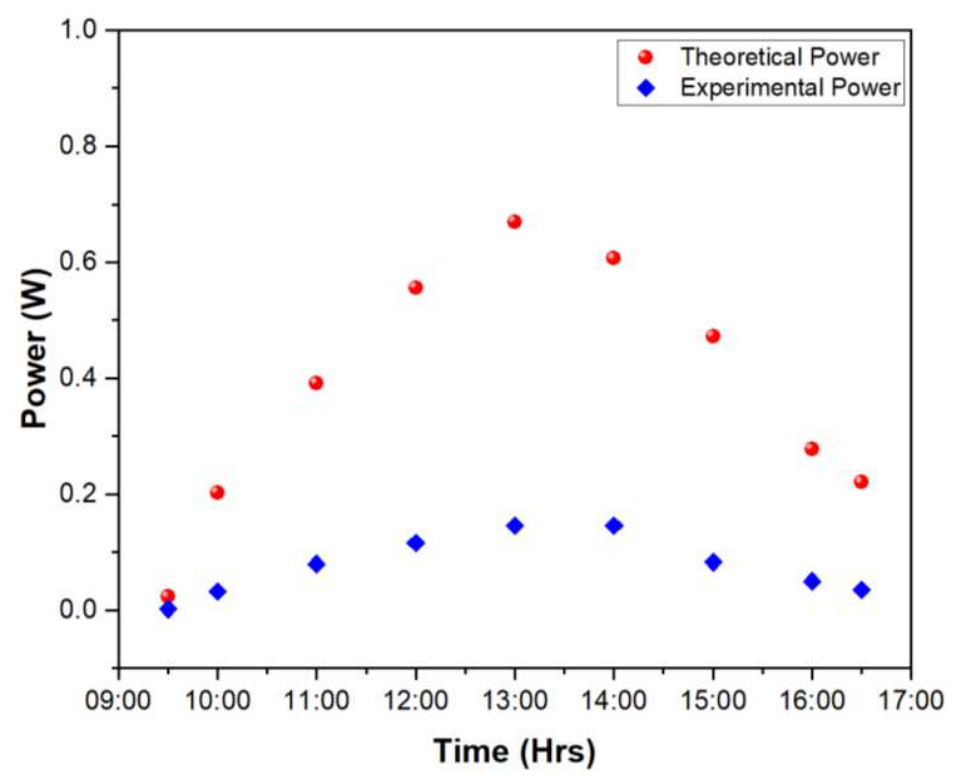


The electrical power generation capability of the TE module can be calculated based on its open-circuit voltage and current intensity. Thus, the maximum obtained power from the

326 Thermoelectric module is the product of voltage and current. The electrical efficiency is too

327 low when compared to other direct energy conversion systems. As a result, using a succession 328 of SEHP to achieve improved electrical efficiency is recommended. As shown in Fig. 7, the produced power is too small at the beginning and the end of the day because of lower solar radiation, lowering the temperature on the TE module's hot side. The TE module's hot side temperature rises as sun radiation rise until it reaches its maximum value of $0.163 \mathrm{~W}$ at 13:40 hours. The generated electric power eventually rises as the temperature difference amid the hot and cold sides of the TE module widens.

334 The maximum electrical energy measured during the experiment was $0.163 \mathrm{~W}$, which was recorded at 13:40 on August 24, 2020, while the cold side temperature of the TEG was sustained at $30^{\circ} \mathrm{C}$. The experimental results show the power output of the TE module between 9:30 and 16:30 hours varies as the heat pipe is subjected to different solar radiation intensity.

The experimental data is collected using an IoT-connected LM35 temperature sensor mounted on the TE module's hot and cold sides. The changes of the predicted and experimental power output of the TEG at various hot side temperatures are plotted in Fig. 7. The output power of the TEG grows as the temperature gradient increases.

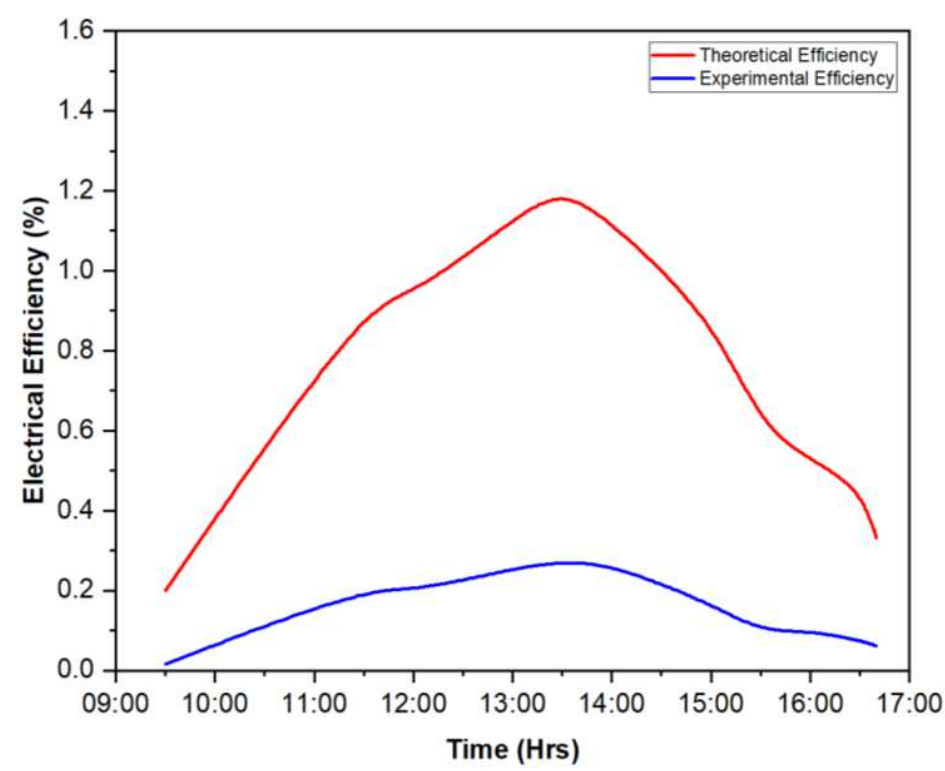


345 The experiment represents the electrical energy efficiency of TEG from 9:30 hr to 16:30 hr.

346 The electrical efficiency produced from each thermoelectric module varies as they are 347 subjected to different radiation intensities at different times. The radiation, on the other hand, 348 peaked at 15:30 $\mathrm{hr}$ and then gradually fell as the evening progressed. The electrical energy 349 efficiency varies in the afternoon due to the system's lag time response to radiation, as seen in $350 \quad$ Fig 8.

\subsection{Experimental Performance parameters of SETHP-TEG with concentrating collector}

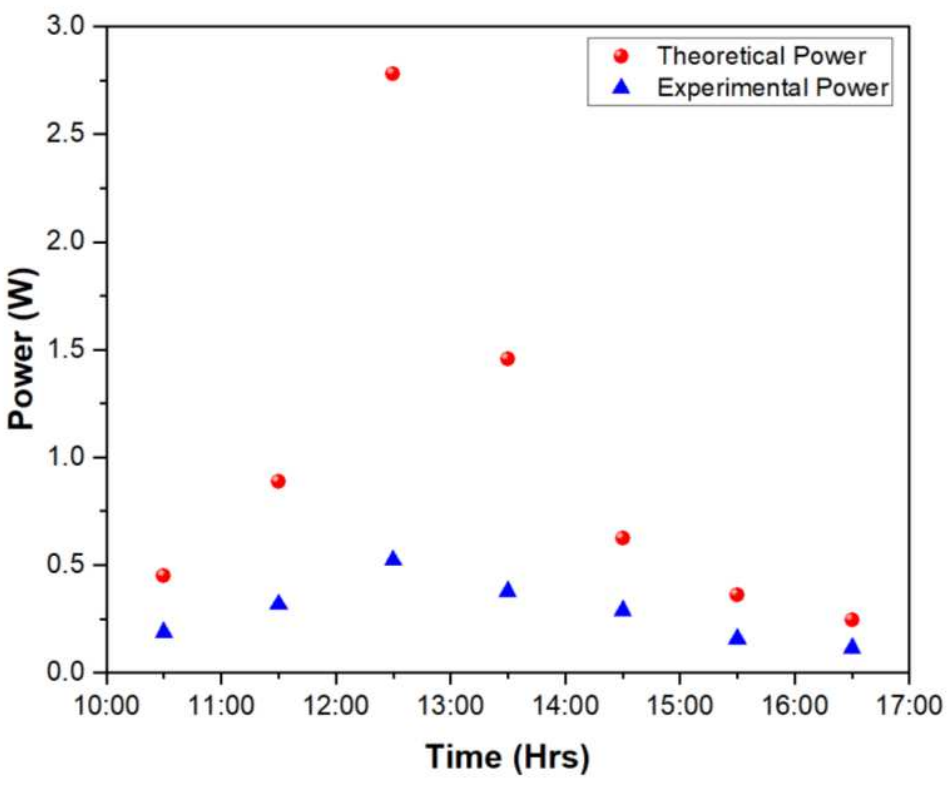

352

353

354

355

356

357

358

359

360

361

362

363

Fig 9. Power Output of SETHP-TEG

The experiment represents the power output of TEG from $10.30 \mathrm{hr}$ to $16.30 \mathrm{hr}$. The power output produced from each thermoelectric module varies as they are subjected to different radiation intensities at different times. The power production fluctuated throughout the afternoon due to the system's lag time response to radiation, as seen in Fig 9. and the output power produced is maximum when compared to the SETHP-TEG system without concentrating collector.

The higher the hot side temperature, the higher the electrical efficiency of TE modules. When PTC is integrated with the SEHP the cold side of the TEG operates at $60^{\circ} \mathrm{C}$ due to the higher heat dissipation, the electrical efficiency of the TE module peaks at $0.16 \%$, which is a lesser value compared to the theoretical efficiency of $0.68 \%$ for static thermoelectric conversion. Due to the thermal resistance of the adhesive substance employed and contact resistance, the temperature gradient across the TEG modules inserted between the Al bars and the cooling fins is smaller than the recorded values at the condenser of the heat pipe and cold 
junction of the TEG. Furthermore, measuring the temperature difference between the cold and hot sides of the TE module is difficult to precise values.

370 The contrasts of theoretical and experimental results with effective real-time data obtained are shown in Figures 9 and 10. The experimental findings and theoretical values are in good agreement. However, the theoretical results with the experimental results of the thermoelectric performance are considerable due to the factors such as contact thermal resistance, thermal resistances of $\mathrm{Al}$ blocks, copper condenser and adhesive material, and heat loss resulting from the air supply.

376

377

378

379

380

381

382

383

384

385

386

387

388

389

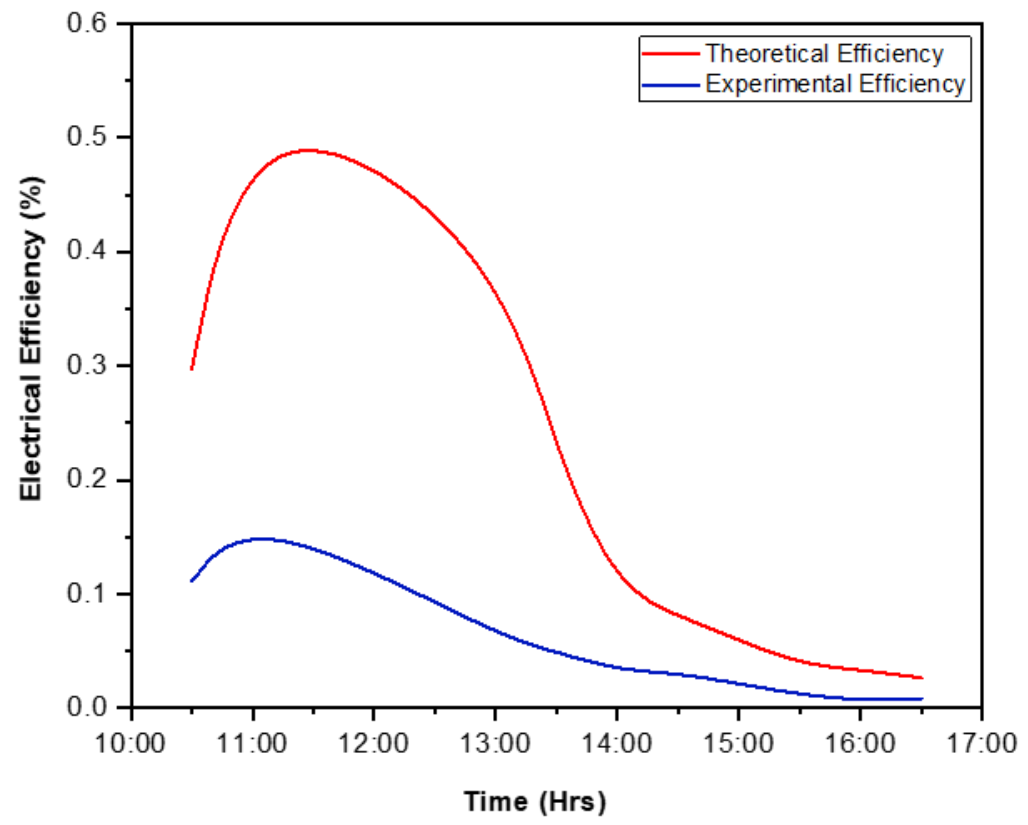

Fig 10. Electrical Energy Efficiency of SETHP-TEG

\subsection{Environmental analysis}

The study was carried out for sustainable development by analyzing the TEGs performance in environmental aspects such as the $\mathrm{CO}_{2}$ emission for the power generated, net $\mathrm{CO}_{2}$ mitigation, and carbon credits for the application of power generation from the solar evacuated tube heat pipe with and without concentrator. TEG converts the most waste heat into electricity, resulting in the maximum $\mathrm{CO}_{2}$ emission of about $2.34 \times 10^{-3} \mathrm{~g} / \mathrm{W}$, net $\mathrm{CO}_{2}$ reduction of 0.027 tones. The highest quantity of net $\mathrm{CO}_{2}$ mitigation translates to the highest carbon credit value, which is roughly 0.681 dollars by assuming $\mathrm{CO}_{2}$ emission at $24.85 \$ /$ tones of $\mathrm{CO}_{2}$ emission (Garud et al. 2021). Further, when the TEG output is boosted, the power output would be higher which in turn adds to the carbon mitigation and will also increase the carbon credit. Thus, the TEG helps in the reduction of carbon emissions. 


\subsection{Boost converter}

The maximum output obtained from the TEG would be $2.99 \mathrm{~V}, 0.18 \mathrm{~A}$, and $0.544 \mathrm{~W}$ from one side of the Al block were considered for the analysis. The input to the boost converter is $2.99 \mathrm{~V}$ and according to equation (11), it is raised to $5.98 \mathrm{~V}$ as the boosted voltage from the converter. This would be directly used for both mobile charging as well as lighting applications at remote areas and at military camps where the community does not have the proper access to electricity.

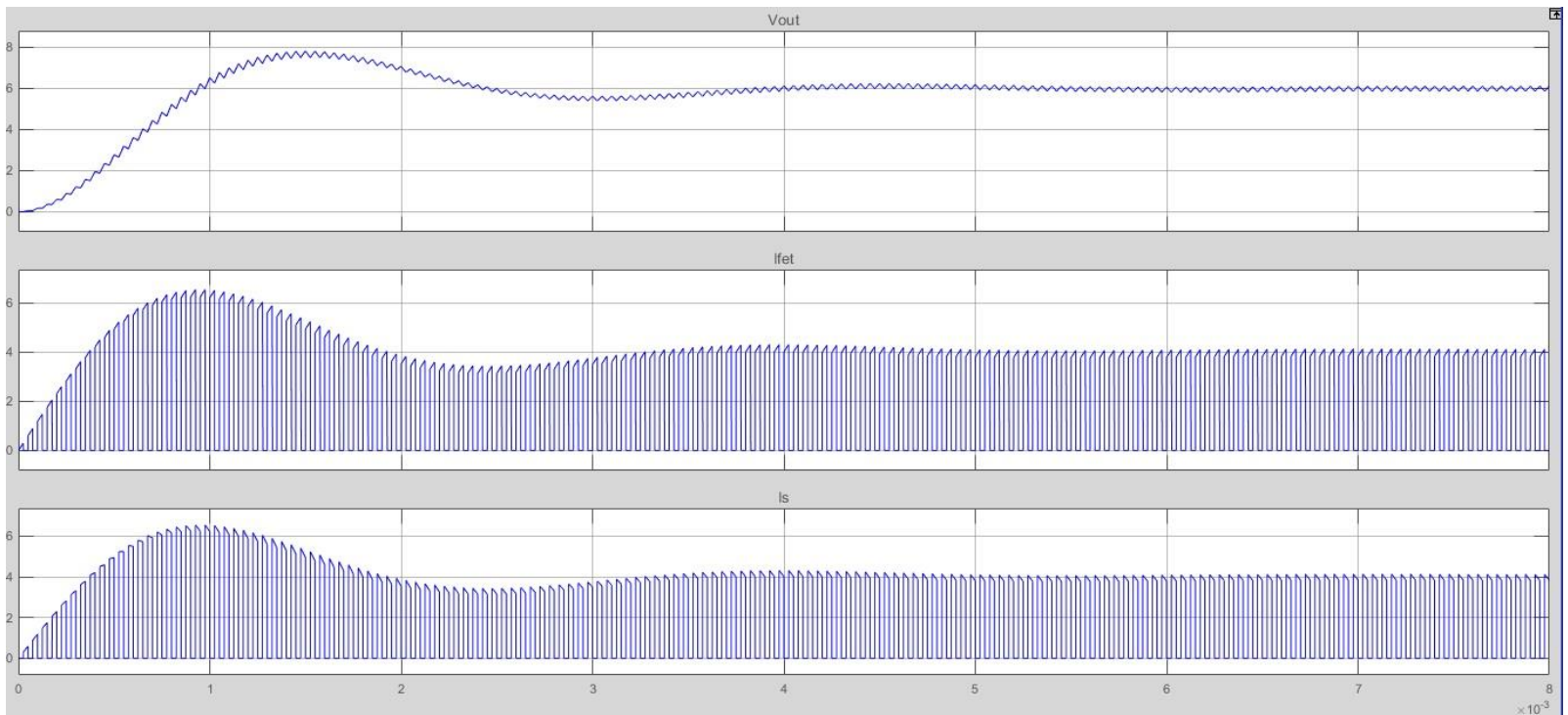

Fig 11. Boost converter with 15V output from MATLAB Simulink model

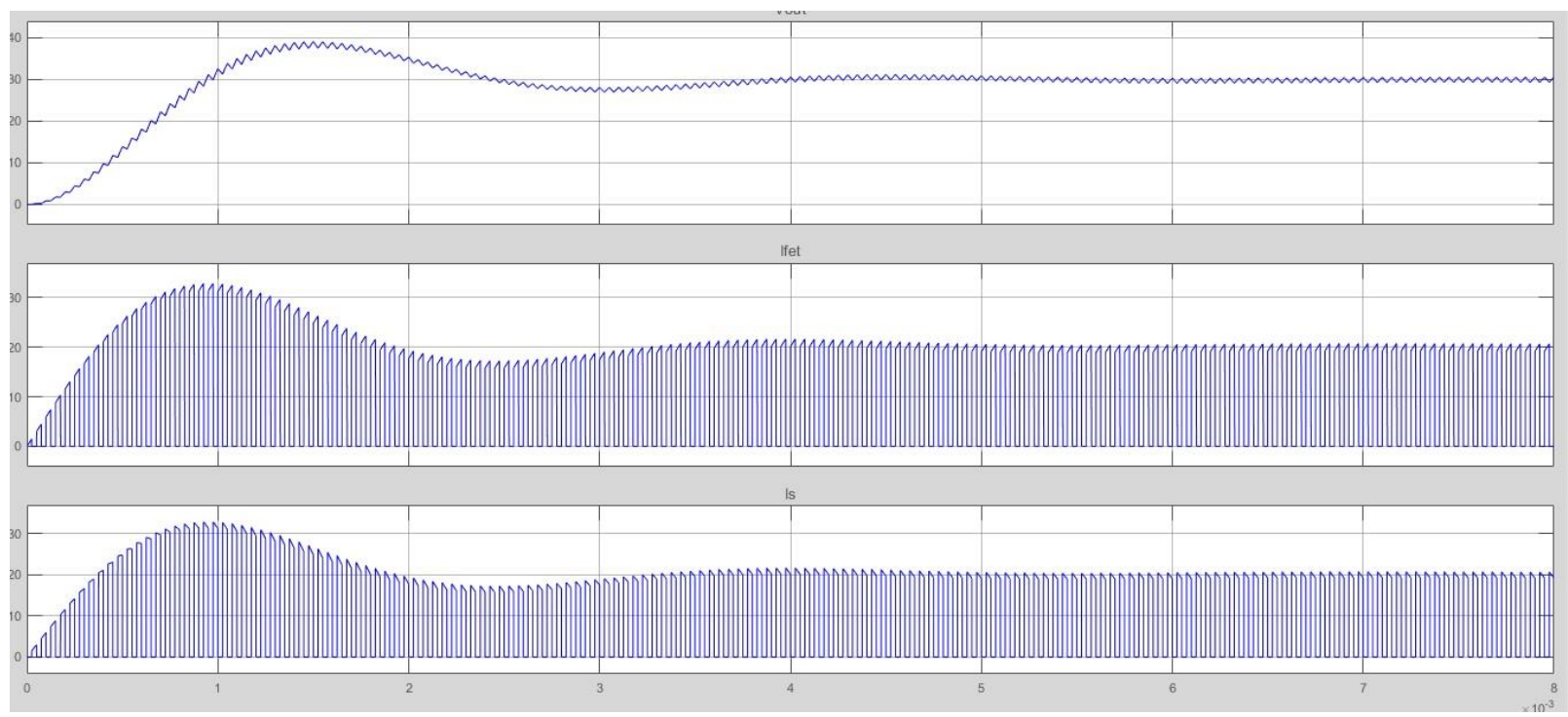

Fig 12. Boost converter with $30 \mathrm{~V}$ output from MATLAB Simulink model 
If 5 tubes were connected in series, which gives 15 voltage supply with 2.72 watts will be obtained from the thermoelectric generator. This $15 \mathrm{~V}$ will be input to boost the converter which can be boosted to a $30 \mathrm{~V}$ supply that can be utilized for higher loads. This part was analyzed using the MATLAB Simulink model to demonstrate and validate the results. Fig. 11 shows the boosted $15 \mathrm{~V}$ output voltage concerning time and Fig. 12 shows the boosted 30V output from the boost converter. Hence the boost converter model in MATLAB Simulink was analyzed and results were displayed in Fig 11. The MATLAB Simulink model result proves the proposed method's accuracy as plotted in Fig 12.

\section{Conclusions}

To generate electricity and heat power, a new cogeneration system was tested using a solar evacuated tube system and thermoelectric modules. The performance parameters of the solar evacuated tube thermoelectric generator were studied for varied hot and cold side temperatures using thermodynamic relations. The performance of thermoelectric power generation systems can be improved by using them in hybrid systems. It is recommended to use at least 6 lenses to attain maximum electrical power (approximately $6 \mathrm{~W}$ ) from one TE module, according to recorded statistics and technical data in the TE module's user guide. The collected results demonstrated that the proposed arrangement can be used in a variety of applications that require thermal and electrical power to diminish fossil fuel usage and $\mathrm{CO}_{2}$ emissions.

In the experimental investigation, the total electrical efficiency of thermoelectric modules fluctuated according to the radiation pattern. The maximum voltage, output power, and electrical energy efficiency of the thermoelectric generator are $1.02 \mathrm{~V}, 0.152 \mathrm{~W}$, and $0.311 \%$ respectively for the SETHP-TEG system without concentrating Collector and 2.99V, 0.544W, and $0.16 \%$ respectively for SETHP-TEG system with concentrating collector. With an atmospheric air temperature of $300 \mathrm{~K}$, solar radiation between $400 \mathrm{~W} / \mathrm{m}^{2}$ and $2000 \mathrm{~W} / \mathrm{m}^{2}$ has been considered. The output power generated from the thermoelectric generator per tube was maximum up to $2.99 \mathrm{~V}$ according to the fluctuations from solar power and using boost converter it was raised to $5.98 \mathrm{~V}$. Power output can be improved by using a thermoelectric module with a higher temperature resistance and a better generator design. The TEG power increases with temperature gradient and it is further improved with using of a power converter. Therefore, the power can be distributed to electrical loads in remote areas where the electrical network does 
based TE model will be preferred for forecasting the desired results. Also, the environmental analysis was carried out for the TEG module for analyzing the carbon emission per Watt, carbon mitigation, and carbon credit and its results are $2.34 \times 10^{-3} \mathrm{~g} / \mathrm{W}, 0.027$ tonnes, and

440 0.681dollars respectively for a TEG module and if it boosted carbon credits would increases.

441 Thus, the TEG involves in the reduction of carbon emission and this would be more effective 442 when it is coupled with the solar evacuated tube heat pipe since it is a renewable energy system.

443 The theoretical analysis reported in this study may aid in the design of solar energy power 444 generation. Although the thermoelectric generator's power output and Combined Efficiency 445 are low, with new thermoelectric materials with a higher figure of merit and a boost converter, 446 these types of systems will become more important in the future. Because there is a large 447 market for evacuated glass tube solar collectors in China, and it is simple to manufacture the 448 SHP-TEG system technically based on a solar evacuated tube solar collector system, the SHP449 TEG system will be cost-effective in the near forthcoming, especially with the decreasing price 450 of thermoelectric materials.

451

452 Availability of data and materials: The experimental data collections supporting the results 453 of this article are included within the article.

454 Funding: Not applicable.

455 Ethics approval and consent to participate: Not applicable.

456 Consent for publication: Not applicable.

457 Conflict of interests: The authors declare that they have no competing interests.

\section{Declaration of competing interest}

The authors declare that they have no known competing financial interests or personal

460 relationships that could have appeared to influence the work reported in this paper.

\section{Author's contribution}


who equally contributed in the preparation of the Manuscript. Conceptualization,

Methodology, Resources, Formal analysis.

Natesan, SabariMuthu Muthusamy, - Data Collection, Writing - original draft preparation,

review and editing, Formal analysis.

review and editing, Supervision and investigation.

470

\section{References}

472

Ahıska R, Mamur H (2016) A review : Thermoelectric generators in renewable energy

Ali H, Sahin AZ, Yilbas BS (2014) Thermodynamic analysis of a thermoelectric power generator in relation to geometric configuration device pins. Energy Conversion and Management 78:634-640. https://doi.org/10.1016/j.enconman.2013.11.029

Bildirici, M., 2018. Impact of military on biofuels consumption and GHG emissions: the evidence from G7 countries. Environmental Science and Pollution Research, 25(14), pp.13560-13568.

Bilgili, F., Kuşkaya, S., Gençoğlu, P., Kassouri, Y. and Garang, A.P.M., 2020. The comovements between geothermal energy usage and CO 2 emissions through high and low frequency cycles. Environmental Science and Pollution Research, pp.1-16.

CAPP (2018) World Energy Needs

483

Chen W, Wang C, Hung C, et al (2013) Modeling and simulation for the design of thermalconcentrated solar thermoelectric generator. Energy. https://doi.org/10.1016/j.energy.2013.10.073

Enescu D (2019) Thermoelectric Energy Harvesting: Basic Principles and Applications. Green

Eydi M, Hosseini SH, Ghazi R (2019) A New High Gain DC-DC Boost Converter with Energy Advances. https://doi.org/10.5772/intechopen.83495 Continuous Input and Output Currents. 2019 10th International Power Electronics, Drive Systems and Technologies Conference, PEDSTC 2019 224-229. https://doi.org/10.1109/PEDSTC.2019.8697693

Garud KS, Seo J-H, Bang Y-M, et al (2021) Energy, exergy, environmental sustainability and economic analyses for automotive thermoelectric generator system with various configurations. Energy 122587. https://doi.org/10.1016/j.energy.2021.122587 
Goldsmid HJ (2014) Bismuth Telluride and Its Alloys as Materials for Thermoelectric Generation. 2577-2592. https://doi.org/10.3390/ma7042577

He W, Su Y, Wang YQ, et al (2012) A study on incorporation of thermoelectric modules with evacuated-tube heat-pipe solar collectors. Renewable Energy 37:142-149. https://doi.org/10.1016/j.renene.2011.06.002

Karabetoglu S, Sisman A, Ozturk ZF, Sahin T (2012) Characterization of a thermoelectric generator at low temperatures. Energy Conversion and Management 62:47-50. https://doi.org/10.1016/j.enconman.2012.04.005

Karthick K, Suresh S, Muaaz M, et al (2019) Evaluation of solar thermal system configurations for thermoelectric generator applications : A critical review. Solar Energy 188:111-142. https://doi.org/10.1016/j.solener.2019.05.075

Kishita Y, Ohishi Y, Uwasu M, et al (2016) Evaluating the life cycle CO2 emissions and costs of thermoelectric generators for passenger automobiles: A scenario analysis. Journal of Cleaner Production 126:607-619. https://doi.org/10.1016/j.jclepro.2016.02.121

Kishita Y, Uwasu M, Takeda H, et al (2014) ASSESSING THE GREENHOUSE GAS EMISSIONS AND COST OF THERMOELECTRIC GENERATORS FOR PASSENGER AUTOMOBILES: A LIFE CYCLE PERSPECTIVE

Kraemer D, Poudel B, Feng H, et al (2011) High-performance flat-panel solar thermoelectric generators with high thermal concentration. Nature Materials 10:532-538. https://doi.org/10.1038/nmat3013

Lv S, He W, Hu D, et al (2017) Study on a high-performance solar thermoelectric system for combined heat and power. Energy Conversion and Management 143:459-469. https://doi.org/10.1016/j.enconman.2017.04.027

Manikandan S, Kaushik SC (2016) Energy and exergy analysis of solar heat pipe based annular thermoelectric generator system. Solar Energy 135:569-577. https://doi.org/10.1016/j.solener.2016.06.031

Ong KS, Naghavi MS, Lim C (2017) Thermal and electrical performance of a hybrid design of a solar- thermoelectric system. Energy Conversion and Management 133:31-40. https://doi.org/10.1016/j.enconman.2016.11.052

Orr B, Akbarzadeh A, Mochizuki M, Singh R (2016) A review of car waste heat recovery systems utilising thermoelectric generators and heat pipes. Applied Thermal Engineering 101:490-495. https://doi.org/10.1016/j.applthermaleng.2015.10.081

Park H, Lee D, Park G, et al (2019) Energy harvesting using thermoelectricity for IoT (Internet of Things) and E-skin sensors. JPhys Energy 1:. https://doi.org/10.1088/2515$\underline{7655 / \mathrm{ab} 2 \mathrm{f} 1 \mathrm{e}}$

Rozik AS, Tolba AS, El-Dosuky MA (2016) Design and Implementation of the Sense Egypt Platform for Real-Time Analysis of IoT Data Streams. Advances in Internet of Things 06:65-91. https://doi.org/10.4236/ait.2016.64005 
Sridharan M, Devi R, Dharshini CS, Bhavadarani M (2018) PT US CR. Internet of Things. https://doi.org/10.1016/j.iot.2018.11.002

Verma, V., Rana, K.B. and Sharma, S.S., 2021. Experimental study and comparative analysis of modified solar paraboloidal dish-thermoelectric generator systems. Environmental Science and Pollution Research, 28(4), pp.3983-3993.

Veronesi, A., Pecoraro, V., Zauli, S., Ottone, M., Leonardi, G., Lauriola, P. and Trenti, T., 2017. Use of carboxyhemoglobin as a biomarker of environmental CO exposure: critical evaluation of the literature. Environmental Science and Pollution Research, 24(33), pp.25798-25809.

Wang C, Hung C, Chen W (2012) Design of heat sink for improving the performance of thermoelectric generator using two-stage optimization. Energy 39:236-245. https://doi.org/10.1016/j.energy.2012.01.025

winnipeg Emission factors in $\mathrm{kg} \mathrm{CO} 2$-equivalent per unit

Yu S, Du Q, Diao H, et al (2015) Start-up modes of thermoelectric generator based on vehicle exhaust waste heat recovery. Applied Energy 138:276-290. https://doi.org/10.1016/j.apenergy.2014.10.062

Yousefi, M., Damghani, A.M. and Khoramivafa, M., 2016. Comparison greenhouse gas (GHG) emissions and global warming potential (GWP) effect of energy use in different wheat agroecosystems in Iran. Environmental Science and Pollution Research, 23(8), pp.7390-7397.

Zhang M, Miao L, Pu Y, et al (2013) Efficient, low-cost solar thermoelectric cogenerators comprising evacuated tubular solar collectors and thermoelectric modules. APPLIED ENERGY 109:51-59. https://doi.org/10.1016/j.apenergy.2013.03.008

Zoui MA, Bentouba S, Stocholm JG, Bourouis M (2020) A Review on Thermoelectric Generators :

\section{Full Battery TEC1-12706 PELTIER COOLER MODULE}

Hydro (2018b) Reduce your carbon footprint with low-carbon aluminium. https://www.hydro.com/en/about-hydro/stories-by-hydro/reduce-your-carbon-footprintwith-low-carbon-aluminium/. Accessed 4 Sep 2019

Arduino UNO Arduino Uno Rev3. https://store.arduino.cc/usa/arduino-uno-rev3

Blynk Blynk. https://www.blynk.cc/

Arduino Software (IDE) Arduino-Guide. https://www.arduino.cc/en/guide/environment

Texas Instruments Temperature Sensors- LM35

Sparkfun ALC Wi-Fi module- ESP8266 -WRL-13678-SparkFun Electronics
Espressif
Systems
ESP8266EX
Datasheet. https://www.espressif.com/sites/default/files/documentation/0aesp8266ex_datasheet_en.pdf 
Set. 